\title{
Journeying with the Terminally III: Decision-making Issues and Challenges
}

\author{
Benedict Faneye \\ Dominican Institute, 3435 Trindle Road, Camp Hill, PA 17011, USA
}

Received: January 12, 2015 / Accepted: January 15, 2015 / Published: January 30, 2015.

\begin{abstract}
The article intends to present a patient's illness experience while reflecting on the individual's inner struggle. The apparent inconsistencies in the patient's care decisions from time to time could actually be the result of inner unresolved struggle. Care givers and family members could become easily disenchanted and think the patient is being difficult, or simply refusing care. The author will highlight some issues of ethical importance. First, there is individual struggle by the patient in accepting a terminal diagnosis. While the patient may have an intellectual understanding of a diagnosis, spiritually,the patient needs human support in accepting the reality of a terminal condition. Second, there has to be an acknowledgment of the patient's individuality by family and care givers. Third, respect for patient's autonomous decision making right. The author will argue that respect for persons essentially recognizes the autonomy of each individual as a decision maker for the self. This has to be recognized with every individual, especially the most vulnerable. When an individual is not able to actively exercise the decision making power, one could use a surrogate decision maker or an advance directive. The author's goal is to argue that care givers should make terminal care as compassionate as possible by relating to patient's spiritual, psychological and physiological needs.
\end{abstract}

Key words: Terminal illness, respect for persons, autonomy of will, decision-making.

\section{Introduction}

In light of the distinction made by Kleinman between illness and disease whereby the former connotes an individual's lived experience, whereas the latter is often a projection of some theories of bodily disorder [1]. The author intend to portray some of the frustrations experienced by patients in the context of relating to their care givers, as well as inefficiencies of the medical system. Some of these inefficiencies are the results of the medical educational system. The system is engineered by human agents who are often inadequately trained or who lack the personal commitment to their various responsibilities. Kleinman introduces and explains the explanatory models in caring for the chronically ill. These models are unique to patients, families and practitioners since they are justifications about what needs to be done

Corresponding author: Chitu Womehoma Princewill, M.Sc, Ph.D. Candidate, research field: autonomy \& women's reproductive rights. Email:chitu.princewill@unibas.ch. rather than mere policy statement. According to Kleinman, these models provide answers to questions raised by specific illness experiences for patients, families and practitioners as well. Consequently, the inability of practitioners to communicate their models effectively with patients and family, as well as the practitioners' inability to negotiate with patients over conflicts in models would all make rendering an ethical treatment an arduous task [2]. Obviously, two elements of the informed consent process are underscored in this model as well. The element of disclosure and understanding are both implied in the explanatory model. This ensures that the patient truly understands what is crucial to the treatment being presented.

As for the frustrations experienced by patients, when care givers are not caring enough or they simply cannot comprehend the patients' particular situation, i.e. patients' individuality, patients would obviously find it difficult to communicate effectively with care 
givers in such instances. When care givers lack the ability to comprehend a patient's illness, whatever image of the individual that medicine finds becomes the lens through which it defines the patient as it attends to the individual. By so doing, the patient's experience and distinctiveness is often ignored, for in the act of diagnosing a patient's illness, the individual's experience is hardly considered thereby reducing the person to mere disease only focusing treatment on particular organs of the body. Hence, it would be hard for a care giver to either involve a patient in the individual's care decision making process, or even consider the individual as being able to make decisions freely.

Another frustration often experienced by the terminally ill concerns the dying process and their fear about the type of care that they could be subjected to. This fear is not fear of death itself but of the dying process [3]. The frustration and the fear experienced over the dying process essentially points not just at the patient's loss of control, but at something more personal, which is being able to hold on to one's sense of personal dignity. It cannot be overemphasized that when disagreement arises over the type of terminal care that is being provided, it cannot just be concluded that the issue is simply about control. For the patient who is concerned, it is more about the individual's self-esteem and the need to make sure that the care being provided does not go contrary to it. The care that is provided to the terminally ill can be denigrating, which explains some of the frustrations experienced. Hence, respect for human dignity calls the care giver to treat the patient as an end in itself and never as a means [4]. An example of what it would mean to treat a patient as an end would be having the practitioner giving full disclosure in order that the patient can have the full information to make care decisions freely without having any treatment forced on him or her. Without this basic foundational principle at work, the care being provided would effectively be lacking the respect that is due to any human person. Furthermore, respect for human dignity leads to the affirmation of the fundamental good of life regardless of the person. This further underscores the importance of the work of the care givers and how it need not be denigrating.

In the instance of a terminally ill person which is the author's focus, reality is often colored by the illness experience, which means that the patient's decisions would also reflect the individual's illness experience. Such experience can be one of spiritual distress, a feeling of loneliness, loss of functionality, a sense of rejection, or stigmatization. Such illness experience is a lived experience which is manifested in one's daily life. For the patient, one place where this experience is clearly manifested is in the patient's care decision making. The consequence of this experience is an inner struggle within the individual. Furthermore, the inner struggle manifests itself in the patient's inconsistencies as he or she tries to make care decisions from day to day. And those who observe these inconsistencies in the patient, such as family members and care givers could easily come to the conclusion that the patient is being difficult, non-complaint or refusing care. This is often the conclusion if the patient is perceived as not being cooperative with care givers or their plan of care. However, the author will initially highlight two ethical principles as backgrounds in light of the primary focus, namely the care of the terminally ill. Later, the author will take the ethical discourse further into another level by introducing another approach.

\section{Ethical Principles}

There are two principles that would ordinarily be applied to care giving cases. One is respect for person and the other is autonomy. They both focus on the individual and the individual's ability to make decisions for the self either directly or through the means of a surrogate. In caring for the terminally ill, especially when patients are no longer able to personally express their wishes, respect for person serves as moral radar for care givers in decision 
making. Through these principles, decisions are not to be arbitrarily made regarding the individual patient. Each patient rather, in those final moments of life should still have the opportunity of taking part in his or her care to the extent possible by one's condition. The author use the term "moral radar" here depicting how care givers have to determine the morally best course of action to follow in the care of a terminally ill individual. Given the principle of respect for person is derived from informed consent with its individualistic leanings, one could conclude that there is no fixed content to what could be considered morally right conduct. However, to be taken into consideration is the physiological, psychological, social and spiritual aspect of every human person.

Autonomy essentially advocates that the individual should be able to make decisions for the self. The value underscored here is that no one should be deliberately impeded from being able to decide on matters concerning the self. For the terminally ill, at the time when they are no longer able to express themselves, the mechanism to be able to decide on the care one would want at the end of life should have been put in place, with the aid of one's care givers who are well informed of the individual's condition. In such instances, care givers have the responsibility to not only disclose the information but also to ensure that a patient has a good understanding of the disease process and how it might impact the daily living of the patient. This would allow the patient to plan, take charge of certain things and appoint particular individuals to make decisions for him/her when he/she is no longer able to do so as a result of the illness. The value of autonomy is preserved in the fact that a patient's representative makes the patient's wishes known with regards to decision making, essentially representing what is in the patient's best interest.

The two principles discussed above are traditional to bioethics. However, the author would at this point like to embrace an approach not so traditional to bioethics by embracing the two principles espoused by the Universal Declaration on Bioethics and Human Rights (UNESCO, 2005). This declaration stresses respect for human dignity and protection of human rights as one of its aims. Here, the fact that a universal declaration makes a pronouncement on human dignity and how it is to be preserved shows that it is not reserved for a select few but for all moral agents, in all human encounters. Crucial to human dignity is each individual's self-worth and how the person is made to feel like he or she is a person. This declaration essentially calls for respect for that sense of individual self-worth. In addition, the declaration stresses protection for human rights. On the one hand, there is respect for individual self-worth, but on the other hand, there has to be protection for rights of individuals even if there is no awareness of those rights by those individuals. Such rights are inalienable by virtue of the human nature and the characteristic gift of life in every individual.

The principle of respect for person above may seem similar to the principle of respect for human dignity, except for the fact that dignity is not something tangible. Some argue that dignity is a useless concept for the reason that it lacks content [5]. However, for this reason, the author would argue that not only is human dignity viewed as an abstract concept with no actual implication for real human life, but the principle of respect for person which is derived from informed consent with its individualistic tendencies, is often viewed and perhaps mistakenly so as a concept that both engages and respects each individual autonomous person. For the individuals who are not able to express themselves personally, this would be an issue to be addressed which the principle of respect for person has obviously not taken cognizance of in its individualistic leanings. As such, one would have to make a conscious effort while showing respect for person to transcend any physical limitations, which could prove an obstacle. Again, an objection might be raised that there is no significant difference between the two principles and so why the duplicity. The 
author would contend that the difference is indeed in both their source and meaning. The principle of respect for person is derived from informed consent which essentially focuses on the individual person. In light of this, the meaning that is usually drawn out of this principle often leans heavily on privacy and individualism [6]. Whereas, respect for human dignity on the other hand essentially refers to the experience of being, which underscores human giftedness, i.e., the fundamental good of life and the basis for common good [7].

It is a matter of hermeneutics, which underscores the approach taken in how something is embarked upon in order that its meaning may be preserved. The principle of respect for person is intended to serve as a platform upon which individuals could relate to one another within a moral framework that ensures that persons are not abused of certain basic human values. However, this principle has become the pretext for people's individual subjective claims which are often at odds with societal values in instances. However, the principle of respect for human dignity stresses nothing physical but the fundamental good of life as well as the moral sense intrinsic to the human nature. For instance, when a care giver caring for terminally ill patient cares for a dying patient with utmost care and attention till the patient expires, not because he expects the patient to live but simply because he knows that is the right thing to do for his dying patient. It is on the basis of this quality of the human nature and the fact that this is something common to all humans and not just peculiar to a few, in other words, being objective, that it calls for respect for that nature, given its inherent dignity.

\section{Ethical Issues \& Challenges}

The illness/disease distinction stresses the significance of symptoms and disability on the individual [8]. For the terminally ill, the symptoms and disabilities that the individual experiences should be taken by the care giver as basis for involving the patient in the decision making over one's care. Showing respect for the dignity of the patient requires also that care givers actively affirm the patient's condition and offer support as patient's condition dictates. This helps the patient to make a peaceful onward spiritual journey in a terminal condition. In light of the distinction mentioned above, care givers should strive not to project but rather encourage the patient to share personal experiences that might positively enhance the care being provided. By encouraging the patient to share experiences, this too could be therapeutic for the patient because of the bonding between the two. When care givers actively affirm the wholesomeness of an individual's experience, the less likely for issues to arise between the patient, family and care givers in the decision making process over an individual's care. However, when a patient struggles with accepting terminal diagnosis, it does not necessarily mean that the patient lacks an intellectual understanding of the condition, it may well be that the struggle is an indication of one's spiritual state which needs to be addressed. On the part of the care givers and others involved in patient's care, it would be mistaken to conclude that the patient is incompetent. To simply make such conclusion would be consistent with the disease theory whereby the care giver simply projects onto the patient. Not only would such attitude make an effective physician-patient relation difficult, it would essentially make the care being provided to the patient unethical for the fact that the patient is totally excluded from consideration. The challenge here is that others could start to undermine the integrity of the patient and what is in the patient's best interest.

Another issue is the human fear of dying, based on the image of death as passivity and helplessness [9], which often makes some care givers to give false hopes to their dying patient. This not only raises just a spiritual issue of faith but an ethical issue as well. Hope enables the terminally ill to envision a transformed life to come. But, when a care giver 
deliberately misinforms or conceals information just so that the patient can play along, the dignity of the patient is violated since such care may not necessarily address real needs of the patient. This is often what happens when a patient refuses a treatment that care givers support. In such instances, the patient would not have been duly informed of what might happen in order that he or she might make a truly informed consent as per choice of treatment. Now, a care giver who thinks that a particular treatment would benefit a patient and uses deception to proceed, in essence, has not shown any respect for the dignity of the patient per se. Now, if this care giver would find it so easy to dispense with this patient's well-being by denying her the respect due to her dignity, one could surmise that the patient's human rights would obviously not be protected.

- As patient's condition deteriorates, thereby making it difficult to personally express one's preferences concerning daily basic care and comfort measures, care givers should not presume their own preferences would suffice. The patient is the one to decide what happens to the self, and that right is preserved till end of life through the use of advance directive. An issue here is to have either a written advance directive or an appointed representative who can make decisions for the patient when incapacitated. The patient's right to decide for self subsists in either the document or through a representative.

- With the progression of terminal illness and its various symptoms, care givers ought to dialogue with patient's representative(s). This acknowledges the patient's individuality, and it equally offers care givers knowledge of the patient necessary to provide a more effective and comforting care for the individual [10]. Effective pain management, that often poses a challenge, requires a collaborative effort between care givers and patient's family, since the family knows the signs of distress better in the patient.

\section{Conclusions}

The experience of terminal illness is often very conflicting and complex. This experience cannot be reduced to biological process alone without considering the patient's spiritual, mental and psychological well-being as well. As such, care givers have a responsibility to help the patient in facing the illness, i.e., being in solidarity with the one who is suffering [11]. In making care decisions, attention should be given to issues that are of importance to the individual patient. Also, if the medical care system is depersonalized and the patient's experience is lost in the process, this would not encourage a wholesome doctor-patient relationship that could offer a comforting and reassuring care to the patient. Caring for the terminally ill requires more than just the science of medicine. It also calls for sensitivities on the part of the care giver in being able to connect with the human experience of his patient especially in moments of struggles. By making this connection, this would help give the patient some assurance, calm anxieties and enable the individual make informed decisions that would help make those final moments of life for the patient as compassionate and comforting as possible.

\section{References}

[1] Kleinman, A. 1988. The Illness Narratives: Suffering, Healing \& the Human Condition. New York: Basic Books, Inc.

[2] Kleinman, A. 1988. The Illness Narratives: Suffering, Healing \& Human Condition. New York: Basic Books, Inc.

[3] Faneye, B. 2012. Integrating the Informed Consent Process in End of Life Care. Germany: Lambert Academic Publishing, vii.

[4] Kant, I. 2010. Groundwork of the Metaphysics of Morals. Translated by Abbott, K. T. USA: Pacific Publishing Studio, 50.

[5] Macklin, R. 2003. "Dignity is Useless Concept: It Means no More than Respect for Persons or Their Autonomy." British Medical Journal 327 (7429): 1419-20.

[6] Macklin, R. 1992. The Nazi Doctors and the Nuremberg Code: Human Rights in Human Experimentation, edited by Annas, G. J., and Grodin, M. A. New York: Oxford University Press, 240-57

[7] Faneye, B. 2014. "Human Dignity and Human Rights: A 
Universal Language for Bioethics." Philosophy Study 4 (1): 11-9.

[8] Kleinman, A. 1988. The Illness Narratives: Suffering, Healing \& Human Condition. New York: Basic Books, Inc.

[9] Lynch, W. F. 1965. Images of Hope. Baltimore, MD:
Helicon Press, Inc., 246.

[10] Faneye, B. 2012. Integrating the Informed Consent Process in End of Life Care. Germany: Lambert Academic Publishing, 34.

[11] Sulmasy, D. P. 2006. A Balm for Gilead. Washington, DC: Georgetown University Press, 36. 